\title{
Assurance Services: The Expansion Of The CPAs' Traditional Services In Local CPA Firms
}

Ronald O. Reed, (Email: roreed@unco.edu), University of Northern Colorado Thomas Buchman, University of Colorado-Boulder

\begin{abstract}
The accounting profession has and is undergoing change in the traditional services that they are providing to their clients. This change is due to market and technological factors, such as: competition in the industry, demand for timely and relevant information for decision-making, demand for reliability of that information, and many other factors that are a result of the shift into an information and service oriented society. The profession is trying to change with these conditions. In 1993, the AICPA identified attestation services as the area earmarked for growth. Today, attestation services have been expanded into a new area of services referred to as, assurance services. Assurance services are considered the wave of the future, as well as, the lifeboat needed to keep the profession afloat.
\end{abstract}

This study surveys local CPA firms in order to determine if they are changing and moving into the new assurance services area. This study addresses whether local firms are following the projected slow growth trend towards attestation and away from historically financial services. Also, this study addresses the research results of the Special Committee on Assurance Services to determine whether local CPA firms are performing assurance services, whether they are experiencing growth or decline in specified areas, and whether they are using the suggestions and recommendations of the Assurance Services Committee.

The results indicate that attestation services appear to be continuing to grow at the modest growth trend that was projected in the 1993 study. There has been and appears that there will continue to be a move toward more attestation services, but that traditional services will still be very important. However, the assurance services are not experiencing the same sort of growth as attestation services. This lack of growth could be attributable to several factors.

\section{Introduction}

ne of the most traditional roles of CPAs has been the audit of histori-cal financial statements. The ac-counting profession has long been the primary server of the public's need for reliable information concerning companies' financial performance and condition. The role of the independent

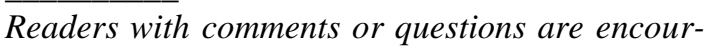
aged to contact the authors via email.

CPA was to provide an objective examination of the financial statements of companies and to render an opinion on the fairness of those statements. The audit function was strictly reserved for the CPA because the CPA possessed a level of expertise as well as an attitude of independence from the organization. In addition to the audit function, other services considered to be traditional to CPAs are those that are tax-related, and those related to management consulting, personal financial planning, or compilation and review.

Over the past twenty or so years, the public accounting profession began expanding from tra- 
ditional services to include a broader range called attestation services. These services have been around since the turn of the century, but they were not considered traditional services offered by CPAs. In fact, most CPAs did not provide them largely because they were not as closely related to financial statement associations as many of the traditional services. However, those CPAs who did perform them did so because the services had a link to verification and examination of information, much like an audit. Attestation services involve providing “....an appropriate level of assurance on a written assertion prepared by a client or third party. The written assertion must be capable of evaluation against reasonable criteria and must also be capable of reasonably consistent estimation or measurement" [AICPA, Attestation Standards No. 1]. These services encompass the traditional ones like an audit, along with review and agreed upon procedures and services, but they also include many engagements that are much broader than CPA financial statement associations. The types of attest services that were identified in the Statement on Standards for Attestation Services (SSAE) No. 1 include engagements related to information supplementary to financial statements, budget compliance, financial forecasts and projections, statistical survey results, and many others.

In the 1990's several factors have changed the CPA profession and, consequently, have changed the traditional services offered by the profession. First, over the years, beginning in the 1980's, the auditing service area has become less profitable because of competition and increases in legal liability insurance. Second, there has been an expanding importance placed on the assurance function by parties making decisions. And last, many changing factors in our overall economy, such the role of technology in the production of reliable and timely information and the constant discussion of tax reform, have led to changes in the services offered by the profession. These factors have caused the certified public accounting profession to examine its mix of services and the direction it needs to take to survive in the next century.
As a result of these changes, new broader types of services beyond attestation, called assurance services, have emerged. In many cases, professionals outside the CPA profession are providing similar types of services. These professional services improve the quality of information, or its context, for decision-makers. They are broader than attestation because they don't require a written report or a client's written assertion for the engagement to be performed, but merely have a set of policies or procedures that the accountant can evaluate. These services can enhance other aspects of information quality besides the reliability of the information. The Special Committee on Assurance Services (SCAS), an American Institute of CPAs (AICPA) committee, has indicated six potential new assurance services. These include are (1) electronic commerce assurance, (2) health care performance measurement, (3) entity performance measurement, (4) information systems quality, (5) comprehensive risk assessments, and (6) geriatric care assurance.

\section{Statement of the Problem}

What is wrong with the traditional services being offered by the CPA profession? Unsatisfied consumers have turned elsewhere, usually to nonCPAs, to obtain the services they require. With this turn toward non-CPAs, the profession is at risk of losing revenue unless it changes to meet consumer needs. Robert Elliott, the Chairperson of SCAS, has indicated three reasons why traditional services are no longer meeting the customers' needs: 1) investors and creditors have many other sources of information, 2) audited financial statements arrive after decisions are made, and 3) producer-driven, general purpose one-size-fits all products. These reasons have produced a need for a change in the services that the CPA profession provides.

Elliott and the SCAS have suggested that the new direction our professional services take should be away from the inherently reliable, onesize-fits-all, historical financial statement preparation and towards the relevant, real-time, consumer-driven information preparation and assessment. The SCAS has identified a host of new services that many CPAs find beyond their scope of com- 
petence, and which they lack the expertise to perform. However, these expanded services offer growth opportunities to CPAs who choose to develop competencies and expertise. The AICPA has identified the problems for professionals who remain with the traditional mix of services and has offered suggestions for new opportunities.

Most of the services that the SCAS has recommended may be designed for large city and large CPA firms. The question that this study addresses is whether local firms see these services as opportunities for growth and are willing to offer these new services.

\section{Objective of the Study}

The overall question that is addressed in this study is whether local CPA firms are beginning to offer assurance and attestation services. The relevant issues addressed include:

- Have local CPA offices ever performed attest services other than audits of financial statements?

- What factors caused the local CPA office to decline one or more non-audit attest engagements?

- How much time have local firms spent performing work related to assertions financial in nature and assertions that are non-financial in nature?

- How many non-audit attest engagements did local CPA firms perform in 1993, 1994, 1995, and 1996?

- What percentage of time was spent on more traditional services compared to non-audit attestation functions?

Also, this study will examine whether firms are implementing the changes or are experiencing the trends in assurance services that the AICPA's Special Committee of Assurance Services has recently encouraged. Accordingly, additional research questions in this area include:

- Has the SPAC delivered on its pledge to help local firms deliver these services?

- Where are local firms operating in the "New Assurance Opportunities" Quadrants, which is represented in Figure 1? Where do they see themselves operating in the near future? Will the lower quadrant services still exist in the future? Looking at each quadrant - what is the breakdown of time spent on these services now, and what is the estimated percentage of time to be spent on each service in the future?

- To what extent do local CPA firms see assurance services as being an important part of what they should do?

\section{Review of Related Literature/Resources}

A discussion of the relevant literature follows.

Brackney and Helms published a study in 1996 that focused on the types of attest services that were identified in SSAE No. 1. The study was designed to address the following questions: (1) what is the nature of the attestation services currently being performed; (2) what is the relative importance of attestation services within the portfolio of all services being provided; and (3) what, if any, office- and firm-specific characteristics are associated with the public accounting practices that perform attestation services.

They found that in ten attestation services performed most frequently include seven financial assertions and two non-financial assertions. The services related to information supplementary to financial statements, compliance with debt covenants when financial statements have been audited, financial forecasts and projections, proforma financial information, management discussion and analysis, segment or interim reports, contract costs, descriptions of systems of internal accounting control, and inventory quantities and locations. On the whole, these findings suggest that the attest services being performed most frequently are financial in nature and the subject of guidance initially given in the SASs. The majority of these services are historically closely associated with audits of conventional financial statements.

An additional question explored by the study was the amount of time spent in each area. The results for 1985-1993 indicated an increase in time spent on management consulting, attestation, 
personal financial planning, corporate tax, and review with a decrease in time spent on individual tax, compilation and bookkeeping, and audits of financial statements. Their respondents expected increases in management consulting, personal financial planning, attestation review and decreases in corporate tax, audits of financial statements, individual tax, compilation and bookkeeping during 1993-2000. The CPA firms indicated that there was a continued growth in the extent of services provided and that attestation, management consulting and personal financial planning have increased and will continue to increase gradually while more traditional services will decline.

The firms were also asked if they expected attestation services to be in demand in the future. The study found that "the areas of growth in attestation services appear to be concentrated in nontraditional areas related to details of the company’s operations."

Robert K. Elliott and Don M. Pallais believe that as the CPA profession grows, there are opportunities available for firms of all sizes. The traditional financial statements audit will still be in demand; however, in order to grow, CPA firms must begin to focus on meeting the need for information services. Decision-makers of all sorts want assurance that the information they are basing decisions on is of high quality. Assurance services are the concept that has been proposed as the solution to meet these new needs. They are broadly focused on improving information reliability, relevance or context, and "can be financial or non-financial...be about past events or conditions or about ongoing processes or systems....[and] can be direct...or indirect ... internal or external'. Elliott and Pallais cite the AICPA's Special Committee findings and commitment to provide assistance with the growth process.

Elliott also has pointed out that the audit still has value, but he then goes on to describe why the traditional audit is flawed. It has inherent unreliability, is losing information market share, and is a one-size fits all service. Also, the market is becoming saturated with competitors. Why is there such a movement toward attestation services? Elliott provides three reasons: 1) investors and creditors have many other sources of info, 2) audited financial statements arrive after decisions are made, and 3) producer-driven, general purpose one-size fits all products, are no longer competitive. To address these three issues, the first step for the profession is to adopt a marketing plan for producing what the customer wants- not what the producer wants to produce.

Clyde suggests that the best strategic move is to expand the attest function by increasing the value of the service provided. Expansion involves furnishing customers with new types of information, as information technology allows for more frequent and timely reports. Real-time assurance can provide relevant, timely, and reliable information. According to Clyde, CPAs are in need of several things: re-engineered academic preparation, continuing professional training, new auditing standards, and new professional skills.

The SCAS identified threats to CPAs, opportunities, actions needed to capitalize on opportunities, and how the AICPA will help members. The threats are summarized as the growing trend toward non-CPA competitors encroaching on traditional CPA services. Information technology is also providing information that was once only provided by CPAs. In order to survive the CPA profession must be willing to change.

The SCAS found that CPA firms are already providing "almost 300 different nontraditional services...[which] encompass audit and other attestation services, but include other services as well. They are broader than attestation because they don't require a written report or a client's written assertion and may enhance other aspects of information quality than just reliability...[they] generally differ from consulting services in that...[they] focus on information quality, not on providing advice."

Once again, the focus is placed on the customer and his/her needs. In order to focus on the consumer, the SCAS has created a matrix that compares the services provided by CPAs and the needs of customers (see Figure 1). The lower-left quadrant represents current services being provided. The upper-left quadrant represents servic- 


\section{The Journal of Applied Business Research}

es that can be developed to meet existing customers' needs. These needs include financial and non-financial performance measures, comprehensive and individual risk assessments, and information systems quality. The lower-right quadrant represents reaching new customers using the traditional audit-like services. This quadrant includes process quality and auditing information on the Internet. The upper-right quadrant is where there are customer needs that are currently not being met by any of the services provided. "The committee is working on three of these opportunities...electronic commerce...geriatric assurance.... and health care effectiveness.'

Total firms sent questionnaire

The SCAS has concluded, Fitithes Respoperfires-

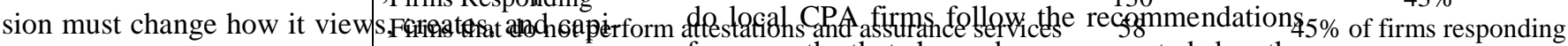

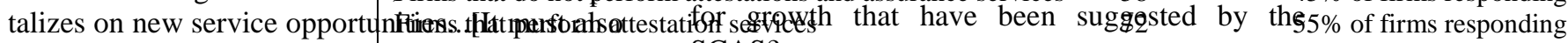
be] more customer oriented, Ferohndfoggerfeteppoth att\&fatiSn and assurance services 35 and nimble." To help the profession, the SCAS has pledged to help practitioners deliver new services by:

- Developing performance

\section{Methodology and Research Design}

the new agreed upon solution. The resources also tend to concede that the opportunities addressed by Robert Elliott and the SCAS is relevant and insightful.

Unfortunately, the Brackney and Helms study had a relatively low response rate and as they report, offices that do more auditing work and offices that are part of larger firms are more likely than other offices to be involved in performing attestation services.

Since the TrabjedityRefpGiBASfinmosarye "local" and the majority of CPAs are employed in local
offices, their results can not be generalized to the offices, their results can not be generalized to the majority of the profession. The quesstion is, then

\section{Percentages $100 \%$} $43 \%$ tice aids.

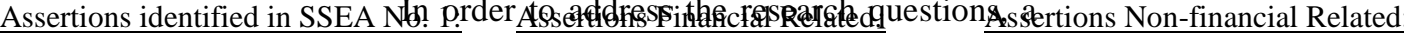

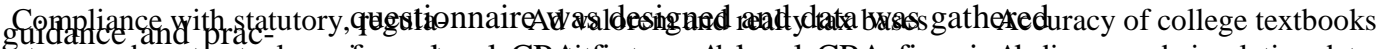

tory, and contractual requifiromentocal CAdtitfirsmsase latecal CPA firm is Aledience and circulation data Descriptions of computer sథfftedras a firBuflege

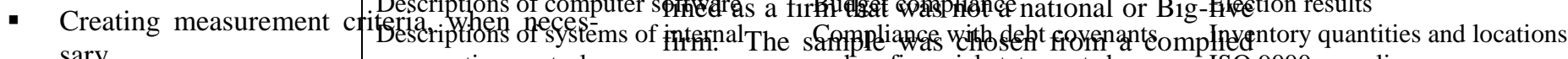
sary.

- Increasing public aware accounting control list derived fromen financial statsments have Priva 9000 compliance services.

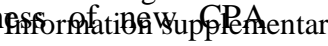

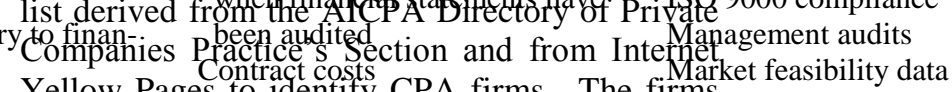

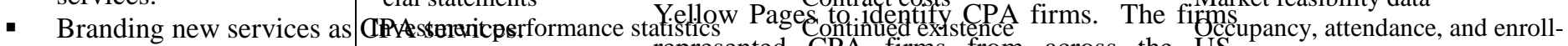

- Developing continuing education offerings.

In summary, there appears to be general agreement that in the past attestation was the solution to the change; however, there is a need for additional growth, either in attestation or in a new area of service. Assurance services appear to be represented Cost teifímbuserfenm across the USent statistics

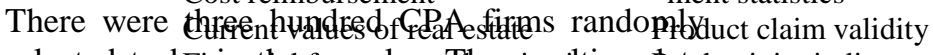

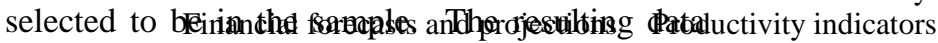
provided inflosmationclaboudatassurance servfodxedules of shopping center retail-

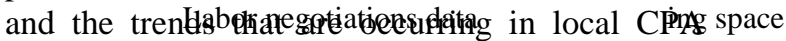

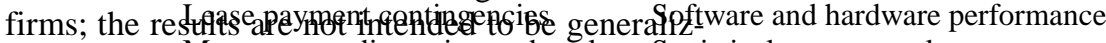
able to large Xpanagement discussion and anal- Statistical survey results ysis

Political contributions and expenditures

Price comparisons with competitors

Pro forma financial information

Reorganization and bankruptcy plans

Royalties

Segment or interim reports 
A questionnaire was prepared based on the Brackney and Helms questionnaire and incorporated the reports issued by the SCAS. The 300 questionnaires were sent out in July 1997 and there were 130 responses, which is a 43 percent response rate. Table 1 provides a summary of the responses.

\section{The Results of the Study}

\section{Attestation Services}

\section{Performance of Attestation Services}

Of the 130 firms that responded, seventy-two have performed attest or assurance services in the past, while fifty-eight have not performed any of these services. Table 1 provides a summary of the respondents.

Respondents were asked to assess the performance frequency of thirty-seven attestation services, which are identified in Table 2, on a five point scale, where $5=$ frequent and $1=$ infrequent. Table 3 indicates the ten most frequent attest services that were identified.

The thirty-seven attestation services were categorized into SSAE No. 1 services, financial related services and non-financial related services. The means for these groupings of services were

Table 3: Types of Attestation Services Performed (N=72)

\begin{tabular}{lcc} 
& & \multicolumn{2}{c}{ Financial } \\
\cline { 3 - 3 } Types of Attest Service & Mean & \multicolumn{2}{c}{ Non-Financial } \\
\cline { 4 - 4 } 1. Financial forecasts and projections & 2.69 & $\mathrm{~F}$ \\
2. Information supplementary to financial statements & 2.62 & SSAE No. 1 \\
3. Compliance with statutory, regulatory, and contractual requirements & 2.33 & SSAE No. 1 \\
4. Compliance with debt covenants when financial statements have been audited & 2.08 & $\mathrm{~F}$ \\
5. Management discussion and analysis & 1.92 & $\mathrm{~F}$ \\
6. Segment or interim reports & 1.92 & $\mathrm{~F}$ \\
7. Pro forma financial information & 1.92 & $\mathrm{~F}$ \\
8. Investment performance statistics & 1.83 & SSAE No. 1 \\
9. Cost reimbursement & 1.75 & $\mathrm{~F}$ \\
10. Inventory quantities and locations & 1.69 & NF
\end{tabular}

Scale on end points: $5=$ performed very frequently, $1=$ not performed very frequently

Table 4: Projected Types of Attestation Services $(\mathrm{N}=72)$

\begin{tabular}{|lcc|}
\hline Types of Attest Service & Mean & Financial \Non-Financial \\
\cline { 2 - 3 } 1. Financial forecasts and projections & 2.92 & $\mathrm{~F}$ \\
2. Information supplementary to financial statements & 2.75 & SSAE No. 1 \\
3. Compliance with statutory, regulatory, and contractual requirements & 2.58 & SSAE No. 1 \\
4. Management discussion and analysis & 2.33 & $\mathrm{~F}$ \\
5. Pro forma financial information & 2.23 & $\mathrm{~F}$ \\
6. Descriptions of systems of internal accounting control & 2.15 & SSAE No. 1 \\
7. Investment performance statistics & 2 & SSAE No. 1 \\
Management audits & 2 & NF \\
8. Compliance with debt covenants when financial statements have been & 1.92 & $\mathrm{~F}$ \\
audited & & $\mathrm{F}$ \\
9. Segment or interim reports & 1.75 & $\mathrm{NF}$ \\
Election results & 1.75 & $\mathrm{~F}$ \\
10. Continued existence & 1.67 &
\end{tabular}

Scale on end points: $5=$ performed very frequently, $1=$ not performed very frequently 
2.2 for SSAE No.1 services, 1.59 for financial services, and 1.33 for non-financial services. Attestation services, which are referred to as the SSAE services, are where the firms believe more of their time is spent. This is the trend that the Brackney and Helms study concluded would occur, which was firms are slowly moving away from the traditional financial services and into the newer, growing areas of services.

Firms were also asked, using the same scale, to assess the projected performance frequency for between 1997 and 2010 concerning the same thirty-seven assertions. Table 4 provides the top ten services that were answered regarding that question.

Using the same groupings, as above, the means for these categories of services were 1.90 for SSAE No.1 services, 1.53 for financial services, and 1.19 for non-financial services. These results indicate the trend toward increased attesta- tion performance, with a declining historically financial focus, is expected to continue into the future. Another interesting fact is that the service that was performed infrequently in Brackney and Helms study and projected to be performed infrequently in the future is the same: schedules of shopping center retailing space.

\section{Nonperformance of Attestation Services}

If attestations are a growing area of service, why are firms declining attest engagements? The seventy-two firms that had performed attest services were asked the reasons that they had declined performing certain attest engagements.

The results, shown in Table 5, indicate that lack of knowledge in the attest subject matter, and lack of training and proficiency in the attest function are the most important reasons.

The fifty-eight firms that have never per-

Table 5: Reasons for Declining Attest Engagements (N=72)

\begin{tabular}{|lc|}
\hline Reasons & $\underline{\text { Mean }}$ \\
Knowledge in the attest subject matter & 5.00 \\
Training and proficiency in the attest function & 4.67 \\
Assertion(s) were not capable of evaluation against reasonable criteria & 3.50 \\
Assertion(s) were not capable of reasonably consistent estimation or measurement & 2.83 \\
Independence issues & 1.80 \\
Other & 1.00 \\
\hline
\end{tabular}

Scale on end points: $5=$ very important, $1=$ not important

Table 6: Factors for Not Performing Attestation Services $(\mathbf{N}=58)$

\begin{tabular}{|lc|}
\hline Factors & $\frac{\text { Mean }}{\text { Services do not fit well with office's business strategy and expertise }}$ \\
Concern over possible additional liability exposure & 4.09 \\
Unfamiliar with the practice standards for these services & 3.44 \\
Little or no client demand for these services & 3.00 \\
Unfamiliar with these services & 3.00 \\
Concern over possible negative effect on perceived audit quality & 2.89 \\
Difficulty competing with non-CPAs in providing these services & 1.89 \\
Other & 1.78 \\
\hline
\end{tabular}

Scale on end points: $5=$ very important, $1=$ not important 


\section{The Journal of Applied Business Research}

formed any attest services were asked why they have not performed these services in the past. Table 6 displays the possible factors and their means for not performing attestation services.

The most important reason for not performing attestation services is that services do not fit well with office's business strategy and expertise. Other important factors were concern over possi-
Volume 17, Number 1

with the practice standards for these services, and little or no client demand for these services.

\section{Assurance Services}

Performance of Assurance Services

The questionnaire asked similar questions concerning assurance services. Of the seventytwo firms that responded that they did attestation

Table 7: Assurance Services Performance Frequency (N=35)

\begin{tabular}{|lc|}
\hline Types & $\underline{\text { Mean }}$ \\
Entity performance measurement & 1.57 \\
Comprehensive risk assessments & 1.33 \\
Electronic commerce assurance & 1.00 \\
Health care performance measurement & 1.00 \\
Information systems quality & 1.00 \\
Geriatric care assurance & 1.00 \\
Other & 1.00 \\
\hline
\end{tabular}

Scale on end points: $5=$ performed very frequently, $1=$ not performed very frequently

Table 8: Projected Assurance Services Performance Frequency $(\mathrm{N}=35)$

\begin{tabular}{|lc|}
\hline Types of Assurance Services & Mean \\
Upper-Left Quadrant: additional services to existing customers & 2.20 \\
Information systems quality (e.g. systems and controls over processing and reporting & 2.10 \\
$\quad$ important internal and external information) & 2.10 \\
Financial and non-financial (entity) performance measures (e.g. customer satisfac- & \\
$\quad$ tion, product quality, process quality, cycle-times) & 1.70 \\
Comprehensive risk assessments (e.g. market, competitive, technological, financial, & 1.70 \\
$\quad$ and people risks) & 1.60 \\
Upper-Right Quadrant: needs not currently served by CPAs or other assurance providers, that appear to be large \\
potential markets in the future & \\
Electronic commerce assurance & 2.30 \\
Health care performance measurement & 1.90 \\
Geriatric care assurance & 1.00 \\
Lowers-Right Quadrant: audit-like services to new types of customers & \\
Auditing information contained on the Internet & \\
Process quality for the benefit of the enterprise's customer & \\
Other &
\end{tabular}

Scale on end points: $5=$ performed very frequently, $1=$ not performed very frequently

ble additional liability exposure, unfamiliarity 
services, only thirty-five have performed assurance services as well as attestations.

Firms that have performed assurance services were asked to identify the frequency with which they performed certain types of assurance services.

The data in Table 7 indicate that local CPA firms are not frequently performing any of the assurance services the SCAS believe are growth opportunities for the profession.

Firms were asked to indicate their projections concerning the performance frequency of assurance services in the future i.e. between 1997 and 2010. Table 8 , showing their responses, is organized as the matrix in Figure 1.

From the responses, it appears that local CPA firms believe that they will be expanding both their client base and the services they provide; however, it also appears that there is little interest in pursuing the risky, but most profitable expansion areas. Overall, the averages in all the areas are low. If these areas are where the profession is moving, as well as where the most opportunity for growth exists, many firms will remain in the traditional services and may expand services into other opportunities. These other opportunities will be discussed in a later section.

Firms were asked to estimate the number of assurance service engagements they provided during each year since 1993. The average number of assurance engagements for 1993 is $4.75,5.375$ in 1994, 6.5 in 1995, and in 1996 the average number of assurance engagements was 7.25. Even though the number of assurance services performed is not large, the number is increasing. It is also important to keep in mind that, as indicated below, these firms have also been declining assurance engagements.

Firms were asked to estimate the percentage of time devoted, or expected to be devoted, to select services for 1993 through 1997 years. The services that CPAs devoted more time to in 1997 than in 1993 include management consulting, personal financial planning, corporate tax, assurance services, and attestation. The services that had less time devoted to them during the same time frame include individual tax, compilation and bookkeeping, and review. Between 1997 and 2000 , the time devoted to personal financial planning, management consulting, attestation, and assurance services is expected to increase. Services expecting to take up less time include individual tax, compilation and bookkeeping, audits of financial statements, review, and corporate tax. It is interesting to note that the both attestation and assurance services are expected to take up more of the CPA's time in the future.

To better compare the time allocated to each service, Table 10 is broken down by year and each service is ranked according to the time allocated to the services. There appears to be very little change in the order of where accountants have

Table 9: Time Devoted to Services

\begin{tabular}{|lccc|}
\hline Services & \multicolumn{2}{c|}{ Percentage of Time per Year } & 2000 \\
Assurance Services & 1993 & 1997 & 3.39 \\
Attestation (other than financial statements) & .88 & 1.63 & 5.29 \\
Audits of financial statements & 2.41 & 2.85 & 16.1 \\
Compilation and bookkeeping & 16.78 & 16.95 & 15.0 \\
Corporate tax & 17.95 & 16.36 & 17.9 \\
Individual tax & 16.50 & 18.13 & 22.0 \\
Management consulting & 29.00 & 26.63 & 12.7 \\
Personal financial planning & 5.61 & 9.42 & 8.39 \\
Reviews of financial statements & 2.33 & 4.43 & 3.12 \\
Other & 3.93 & 3.47 & 39.7 \\
\hline
\end{tabular}


in the past, and expect in the future, to spend their The high averages produced from this question

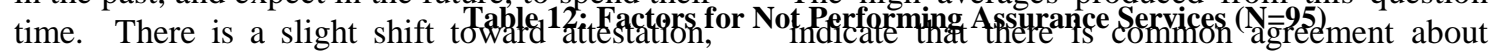
which followstaters findings of both the 1993 study why they declined work, and are shown in Tialde

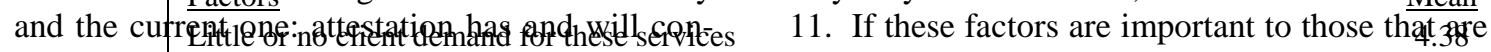

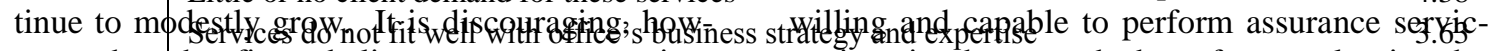

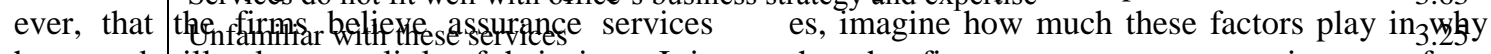

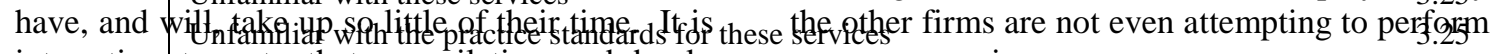

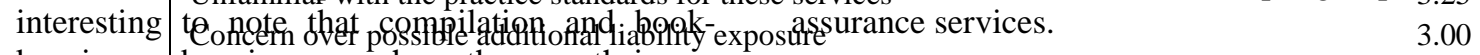

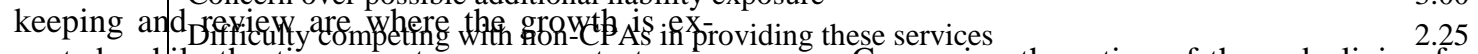

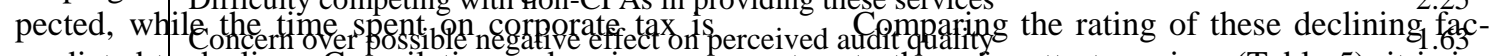
predicted to decline. Compilation and review are tors to those for attest services (Table 5), it is in subsets of assurance services and so will keep the teresting that the order is almost identical: the top

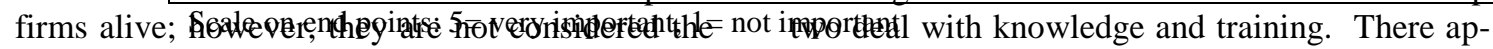
most advantageous services for firms that want to pears to be a common theme: firms are either iggrow. Auditing is viewed as stable, or perbaps noring the performance of these services because flat, which is exactly why the profession is look- they do not see the demand or are declining the

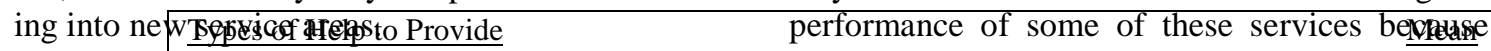
Increasing public awareness of new CPA servicthey do not believe that they have the properzeghl-

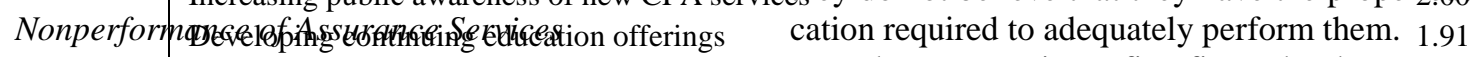
Branding new services as CPA services There were ninety-five firms that have negger

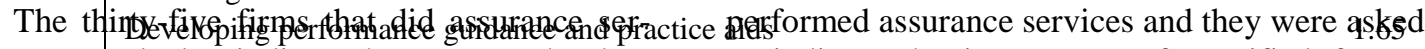
vices were ackedtitf imdistatenthehtreasegns why they to indicate the importance of specified factsors declined any possible assurance engagements. concerning why they had never performed these Scale on end points: $5=$ very important, $1=$ not impertiant.

The results, shown in Table 12, seem to suggest that there is not a perceived demand for assurance services. However, the other studies that have been performed show that such a demand does, in fact, exist. There also appears to be concern over the firm's ability and familiarity with these services. There are a couple of conclusions

Table 10: Time Devoted-Rankings of Services (ranked by year)

\begin{tabular}{|lccc|}
\hline Services & $\frac{1993}{1}$ & $\frac{1997}{1}$ & $\frac{2000}{1}$ \\
Other & 2 & 2 & 2 \\
Compividual tax & 3 & 5 & 5 \\
Audits of financial statements & 4 & 4 & 4 \\
Corporate tax & 5 & 3 & 3 \\
Management consulting & 6 & 6 & 6 \\
Review & 7 & 8 & 8 \\
Attestation (other than financial statements) & 8 & 9 & 7 \\
Personal financial planning & 9 & 7 & 9 \\
Assurance Services & 10 & 10 & \\
\hline
\end{tabular}

$1=$ most important

Table 11: Reasons for Declining Assurance Engagements (N=35)

\begin{tabular}{|lc}
\hline Reason & $\frac{\text { Mean }}{4.25}$ \\
Lack of knowledge in the attest subject matter & 4.00 \\
Lack of training and proficiency in the assurance function & 3.00 \\
Independence issues & 2.75 \\
Assertion(s) were not capable of evaluation against reasonable criteria & 2.75 \\
Assertion(s) were not capable of reasonably consistent estimation or measurement & 2.50 \\
Other &
\end{tabular}

Scale on end points: $5=$ very important, $1=$ not important 
Table 14: Desired Helpfulness for Assurance Services ( $N=35)$

\begin{tabular}{|lc|}
\hline Areas Help Is Needed & Mean \\
Developing continuing education offerings & 3.21 \\
Developing performance guidance and practice aids & 3.11 \\
Branding new services as CPA services & 3.05 \\
Increasing public awareness of new CPA services & 3.00 \\
Creating measurement criteria & 2.79 \\
\hline
\end{tabular}

Scale on end points: $5=$ very important, $1=$ not important

that can be drawn from this study's results. The firms that responded to this questionnaire were mainly small in size and were often from less populated areas. Perhaps, assurance services are primarily being demanded in larger cities, and/or perhaps where clients are demanding these services inquire of larger firms. These are issues that the SCAS needs to address and resolve. Comparing the reasons for not performing assurance services (Table 12) with reasons for not performing attest services (Table 6) a common theme emerges. Even though the factors are ranked a little differently, demand, education, and liability appear to be the major reasons why firms are not performing these services.

\section{SCAS Support for Assurance Services}

The SCAS has declared that they will deliver assistance by providing services in areas they believe will be beneficial to firms. The firms in this study were asked if they have experienced assistance from the committee for offering these services. Table 13 shows the firm's responses to rate the assistance received to implement these new types of services.

These results are not very promising. Even though the highest mean is ranked about in the middle, means are very low, which helps to explain why firms are not providing these services and why they do not see the assurance area as an area with growth potential. It is, of course, important that the public knows about what services are being offered; however, if the firms are not educated, or if they are not provided guidance or base criteria from which to operate, the fact that there are consumers will be of little importance.
Firms were also asked to indicate to what degree they believe these areas will actually help their firm implement or expand their providing assurance services. The firms have ranked these services in a different order than the help they are actually experiencing. From the relatively high means, it is obvious that firms believe that all of these areas are important. These results also help to identify where the AICPA should focus in order to provide the most beneficial help. These results support the reasons given earlier as to why firms are not performing and are declining attestation and assurance engagements: education was the number one reason.

\section{Conclusion}

Attestation services appear to be continuing to grow at the "modest growth trend" that was projected in the Brackney and Helms, 1996 study. There has been, and it appears that there will continue to be, a move toward attestation services and away from dependence on the historical financial services of the past.

Among our firm respondents, assurance services are not experiencing the same sort of growth as attestation services. This lack of growth could be attributable to several factors. One important factor is that the local firms do not demand these services. It is important to note that the respondents were from smaller firms. Large and medium sized firms could, in fact, be experiencing a growth in assurance services. The client base of these firms may demand these services. Perhaps these firms are not located in, or close to, communities where these services are in demand. These firms could also be located near larger firms, which do attract clients requesting assur- 
ance services. Smaller firms also tend to specialize in certain areas, and as indicated in the study, if assurance services, or attestation services for that matter, do not fit into the firm's niche, it is not likely to offer that service.

Even with a list of assurance services, some respondents made notations or answered questions that suggested that they were unfamiliar with what "assurance services" means. Something else to consider is that there may be confusion as what assurance services are.

Is the AICPA helping? The firms are not experiencing an adequate amount of help from the AICPA. Because of the size of the firms that responded, perhaps the AICPA is not reaching the smaller CPA firms. It is evident, however, that these firms do want assistance. It is also evident that the area of assistance that is most desired and needed for both attestation and assurance services is that of education.

\section{Suggestions For Future Research}

The types of services that CPA firms are offering to their clients are steadily expanding. As these services expand, a series of critical research questions arise that warrant future research opportunities. First, it appears that certain services are best suited for certain size CPA firms. As the profession expands services, it is not that all services fit all firms. Research can help identify the best relationship between the size of firm and the services best suited for a specific size firm.

Very closely related to the above issue is the impact on the accounting profession when other professions converge as a result of CPAs expanding their services and other professions encroach on accounting. As CPAs begin to deliver new services that traditionally have been delivered by other professionals, what will the impact be on the accounting profession? For example, as CPAs move into the financial services and insurance areas, what does this mean to the accounting profession? There are many examples of the convergence of professions and the accounting profession needs to examine the impact on its image as convergence takes place.
The last important research area is related to CPA independence. As the profession expands services, the potential for conflicts with independence issues begins to arise. The whole area of impairment of independence needs to be investigated and what services potentially create impairments of independence.

\section{References}

1. AICPA. "Changing the Profession." 1996. Online. Internet. 21 Feb. 1997. Available http://www.AICPA.org/assurance/pre/ctp.htm.

2. AICPA. "Special Committee on Assurance Services." 1996. Online. Internet. $21 \mathrm{Feb}$. 1997. Available http://www.AICPA.org/ assurance/pre/index.htm.

3. AICPA. "The Opportunities." 1996. Online. Internet. $21 \mathrm{Feb} .1997 . \quad$ Available http:// www.AICPA.org/assurance/pre/top.htm.

4. AICPA. "Threats to the Future Economics of Auditing." 1996. Online. Internet. 21 Feb. 1997. Available http://www.AICPA. org/assurance/pre/tfea.htm. "“

5. AICPA. "Chair's Corner." 1996. Online. Internet. 21 Feb. 1997. Available http://www .AICPA.org/pubs/cpaltr/dec96/index.htm.

6. Brachel, John Von. "AICPA Chairman Lays the Foundation for the Future." Journal of Accountancy 180.5 (1995): 64-68.

7. Brackney, Kennard S., and Glenn L. Helms. "Practice Notes: A Survey of Attestation Practices." Auditing: A Journal of Practice \& Theory 15.2 (1996): 83-98.

8. Clyde, Robert D. "Accounting \& Auditing: AICPA's Strategic Planning Committee." Today's CPA 20.3 (1994): 50.

9. Demery, Paul. "Tech News - Microsoft Rolling Out Accounting Linking Product: Technology Drives Assurance Services." The Practical Accountant 28.12 (1995): 14.

10. Elliott, Robert K., and Don M. Pallais. "Are You Ready for New Assurance Services?" Journal of Accountancy 183.6 (1997): 47-51. 
11. Final Report of Special Committee on Assurance Services. Slides. AICPA Council. October 18, 1996. 